\title{
DETERMINATION OF MATERIAL DESIGN VALUES FOR STEEL FIBRE REINFORCED SELF-STRESSING CONCRETE (SFRSSC) STRUCTURES
}

\author{
Martins Suta ${ }^{1}$, Arturs Lukasenoks ${ }^{2}$, Rolands Cepuritis ${ }^{3}$ \\ ${ }^{1}$ SIA “PRIMEKSS”, Latvia; ${ }^{2}$ Riga Technical University, Latvia; \\ ${ }^{3}$ Norwegian University of Science and Technology, Norway \\ martins.suta@primekss.com, arturs.lukasenoks@rtu.lv, \\ rolands.cepuritis@ntnu.no
}

\begin{abstract}
With steel fibre reinforced concrete (SFRC) technology advancing for multiple decades already there are more and more fields that see the material as an opportunity of making structures more efficient whether cost-wise, time-wise, material-wise. Multitude of design guidelines have been produced over the years and many testing setups have been invented and standardized for the sole purpose of getting to know the capabilities of the material. Yet, the material is still being developed further with such materials being introduced as steel fibre reinforced self-stressing concrete (SFRSSC) among others. The current design guidelines show how to arrive to a structure from material properties of SFRC and SFRSSC obtained from testing. Nevertheless, the testing methods for this material are very different to each other and, although, with one and the same purpose, they share very little in terms of what they are actually capable of showing and how relevant it actually is to the structure to be built. To provide an overview of how different methods of testing with their inherent pros and cons evaluate the same material a series of tests have been devised to capture the material capabilities of SFRC. Depending on the test method, it can be seen that the difference in the results can be as low as none and as high as $15 \%$ in terms of load bearing capacity of the material. This difference translates to having a slab on piles with thickness of $210 \mathrm{~mm}, 240 \mathrm{~mm}, 235 \mathrm{~mm}$, respectively, for tests according to SIA 162/6, ASTM 1550C, EN 14651 ceteris paribus, showing that from perspective of leanest design tests according to SIA162/6 are the best.
\end{abstract}

Keywords: SFRC, material resistance.

\section{Introduction}

Flat concrete structures, slabs, walls, shells, are used more and more throughout the world [1-3], and there are multiple testing procedures developed to assess strength characteristics of materials used in such structures. Most of the mentioned structures are working in flexure, thus flexural strength is a characteristic essential for the design of mentioned structures. This is true for any fibre-reinforced structure. New developments have been made in fibre-reinforced concrete (FRC) technology including the usage of steel fibre reinforced self-stressing concrete (SFRSSC).

SFRSSC offers some advantages over traditional concrete. As discussed elsewhere (e.g. Error! Reference source not found.; Error! Reference source not found.), shrinkage-compensating concretes like SFRSSC can be engineered to compensate for long-term (drying) shrinkage with an initial expansion force, that helps reduce the potential for shrinkage-induced cracking. Further, the number of joints can be reduced or eliminated due to the improved shrinkage situation with SFRSCC. The aim of the study presented herein was to assess the flexural strength properties that can be tested by readily available testing methods to provide a basis for the calculation of SFRC and SFRSSC structures and compare the results in a structure. Previous research has looked at concrete tensile strength improvements, yet flexure has not been accounted for [6].

\section{Experimental Programme}

\subsection{Steel fibre reinforced concrete (SFRC) composite composition}

The material composition used in this study is presented in Table 1 below. Cemex CEM I $42.5 \mathrm{~N}$ cement was used as the binder. Sand in 0-4 mm fraction from Garkalnes Grants and crushed dolomite aggregate from Pḷavinas DM quarry were used as the aggregate. PrīmXFlow high range water reducing admixture (HRWRA) from Primekss was used to adjust the concrete consistency. The waterto-cement ratio of the concrete mix was set to 0.47 . Hooked-end steel fibres $(50 \mathrm{~mm}$ long and $0.75 \mathrm{~mm}$ in diameter) from ArcelorMittal were used as the reinforcement.

The SFRC composite was prepared in a planetary mixer at a full-scale concrete batching plant following a standard 120 -second mixing procedure. Fibres were gradually added in the mixer of the batching plant while the concrete was mixed. 
Material composition for steel fibre reinforced

Table 1 composite concrete

\begin{tabular}{|c|c|}
\hline Material & $\begin{array}{c}\text { Content, } \\
\mathrm{kg} \cdot \mathrm{m}^{-3}\end{array}$ \\
\hline CEM I $42.5 \mathrm{~N}$ cement & 380 \\
\hline Water & 180 \\
\hline $0-4 \mathrm{~mm}$ sand & 768 \\
\hline $\begin{array}{l}\text { 4-8 mm crushed } \\
\text { limestone }\end{array}$ & 444 \\
\hline $\begin{array}{l}8-16 \mathrm{~mm} \text { crushed } \\
\text { limestone }\end{array}$ & 618 \\
\hline PrīmX FlowHRWRA & 3.8 \\
\hline $\begin{array}{l}\text { Hooked end steel fibres } \\
(L-50 \mathrm{~mm}, \\
d-0.75 \mathrm{~mm})\end{array}$ & 40 \\
\hline $\mathrm{w} / \mathrm{c}$ ratio & 0.47 \\
\hline
\end{tabular}

The prepared SFRC mixture was then delivered with a typical concrete truck mixer to the place of casting the samples. Fresh concrete workability was determined by measuring the concrete slump value according to EN 12350-2 Error! Reference source not found.. The consistency measurement results for the concrete after the addition of the fibres was $19 \pm 1 \mathrm{~cm}$ (shown in Fig. 1).

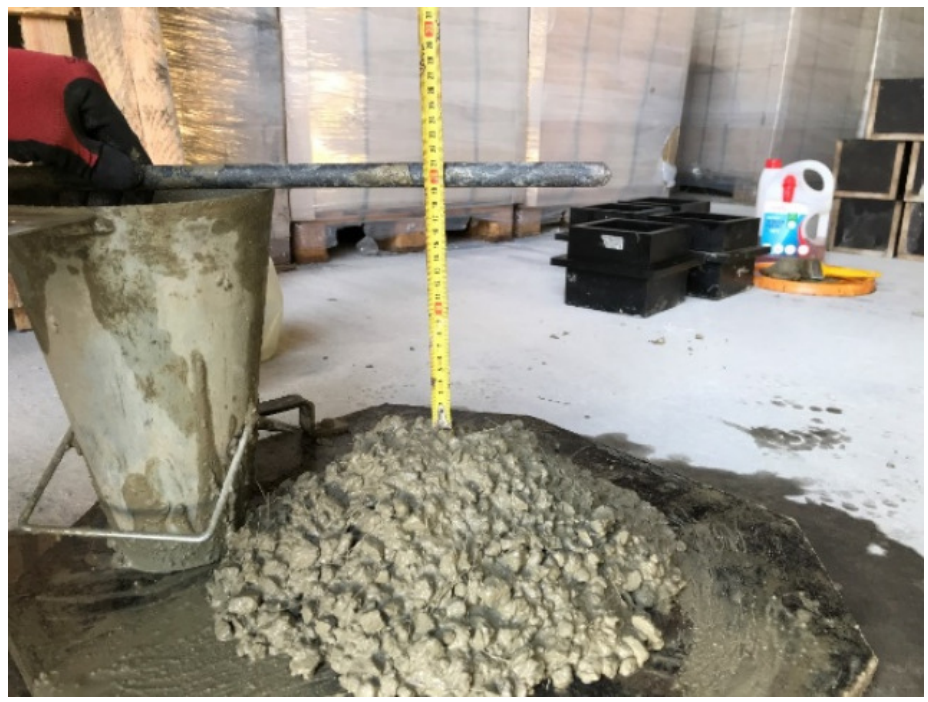

Fig. 1. Consistency measurement of tested concrete

\subsection{Specimen preparation}

The following sets of samples were prepared for further mechanical testing of the hardened material:

- Set of 5 standard cubes with a size of $150 \times 150 \times 150 \mathrm{~mm}^{3}$ were manufactured for determination of the compressive strength. The samples were demoulded and stored in water after $24 \mathrm{~h}$, and then tested at the 28 days age.

- Set of 7 beam samples with a size of $150 \times 150 \times 600 \mathrm{~mm}^{3}$ were manufactured (shown in Fig. 2 on the left). The concrete samples were demoulded after 24 hours and put in water for 28-day wet curing. After curing, the samples were prepared and tested in three-point bending in accordance with EN14651 Error! Reference source not found.. During the testing, the load and crack mouth opening displacement (CMOD) were measured. Testing was carried out with load rate of $0.25 \mathrm{~mm} \cdot \mathrm{min}^{-1}$. 
- Two sets of 7plate samples each with a size of $800 \mathrm{~mm}$ in diameter and $90 \mathrm{~mm}$ thick for testing according to ASTM 1550C Error! Reference source not found. and $100 \mathrm{~mm}$ thick for testing according to SIA 162/6 Error! Reference source not found. were manufactured (shown in Fig. 2 on the right).
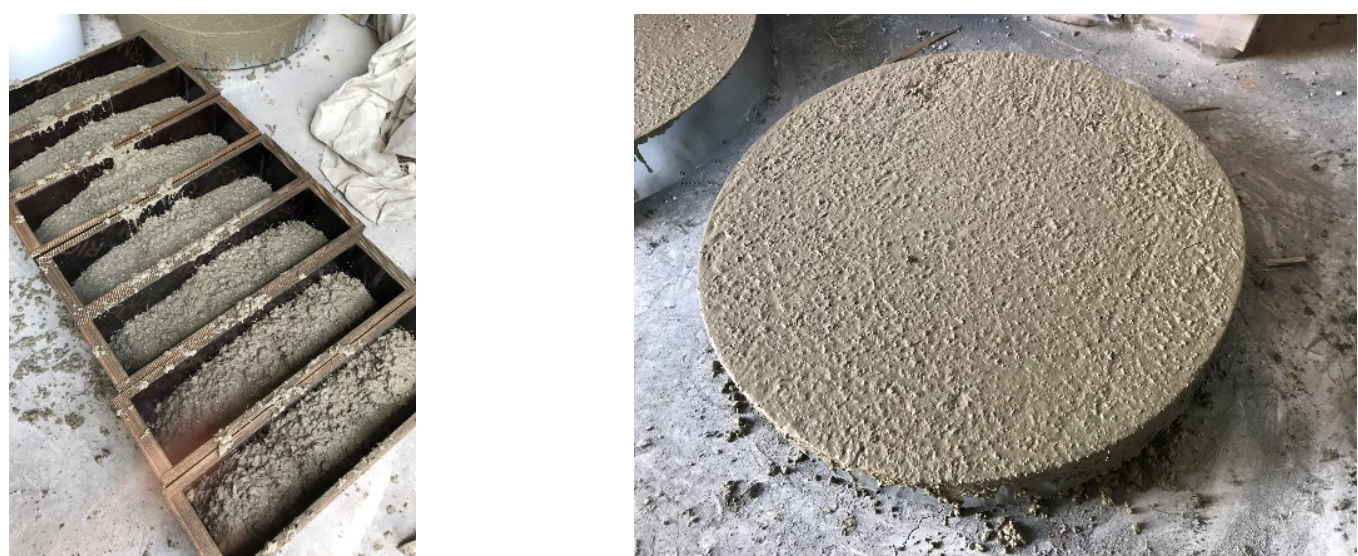

Fig. 2. Specimens during preparation according to EN14651 and SIA 162/6

\subsection{Testing}

The plate testing was carried out according to the said two standards (ASTM with three supports and SIA continuously supported slab). Load and deflection in the middle span were measured. The loading and support scheme is shown in Fig. 3 on the left and plate testing with three magistral cracks on the right.
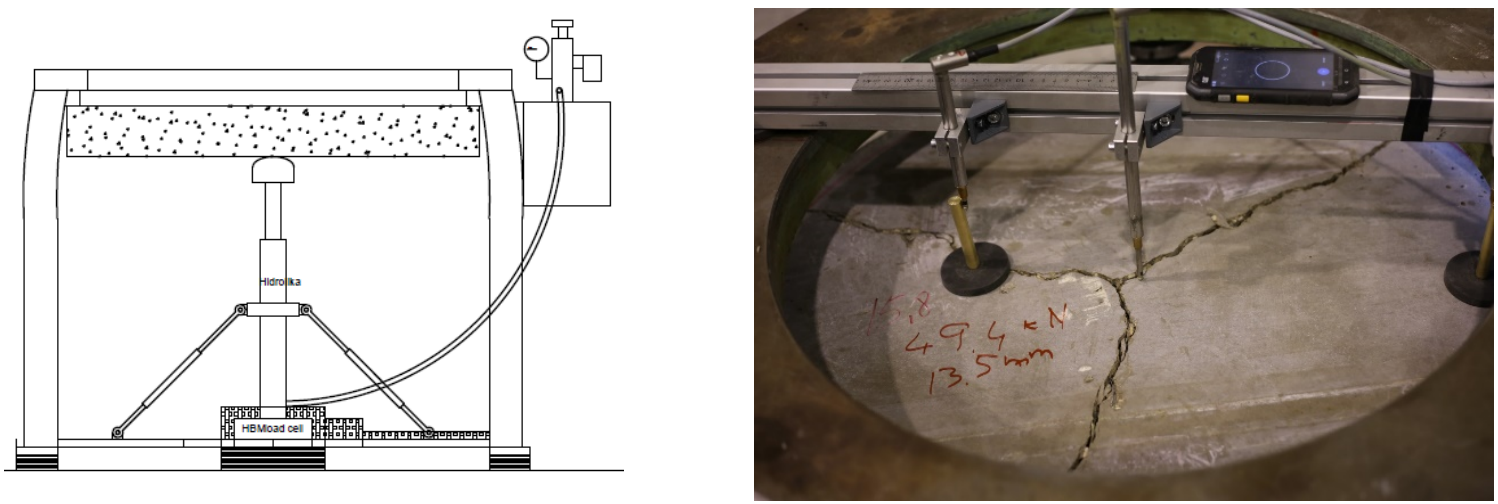

Fig. 3. Round panel test setup

\section{Results}

\subsection{Compressive strength}

The determined mean compressive strength of the SFRC was $52.1 \mathrm{MPa}$ with the standard deviation of $5.31 \mathrm{MPa}$ and thus the coefficient of variation of $10.21 \%$.

\subsection{Load-deflection relationship of the tested beams and round panels}

The determined mean load-deflection relationships for the three applied flexural performance testing methods are shown in Figures4 - 6 below, a summary of the results shown in Fig. 7. The corresponding data points in order to compile the curves with the mean flexural performance results are also shown in Table 2.

From the results presented in Table 2 it can be seen that the coefficient of variation is decreased from $9.4 \%$ for EN14651 as the maximum to $2.6 \%$ for SIA162/6 as the minimum. This reduction can be attributed to statical redundancy of the testing method, where the simply supported beam of EN14651 is the least redundant and the continuously supported slab of SIA162/6 is the most redundant. 


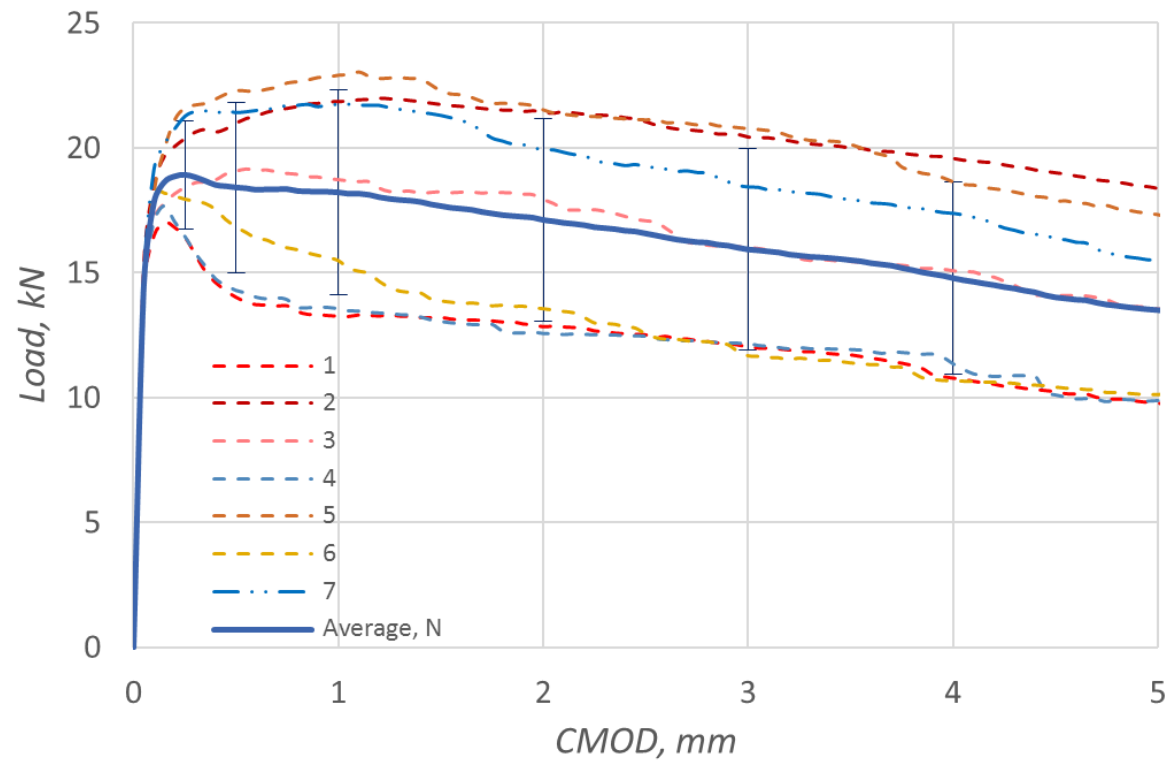

Fig. 4. Load-deflection relationship diagram for EN 14651

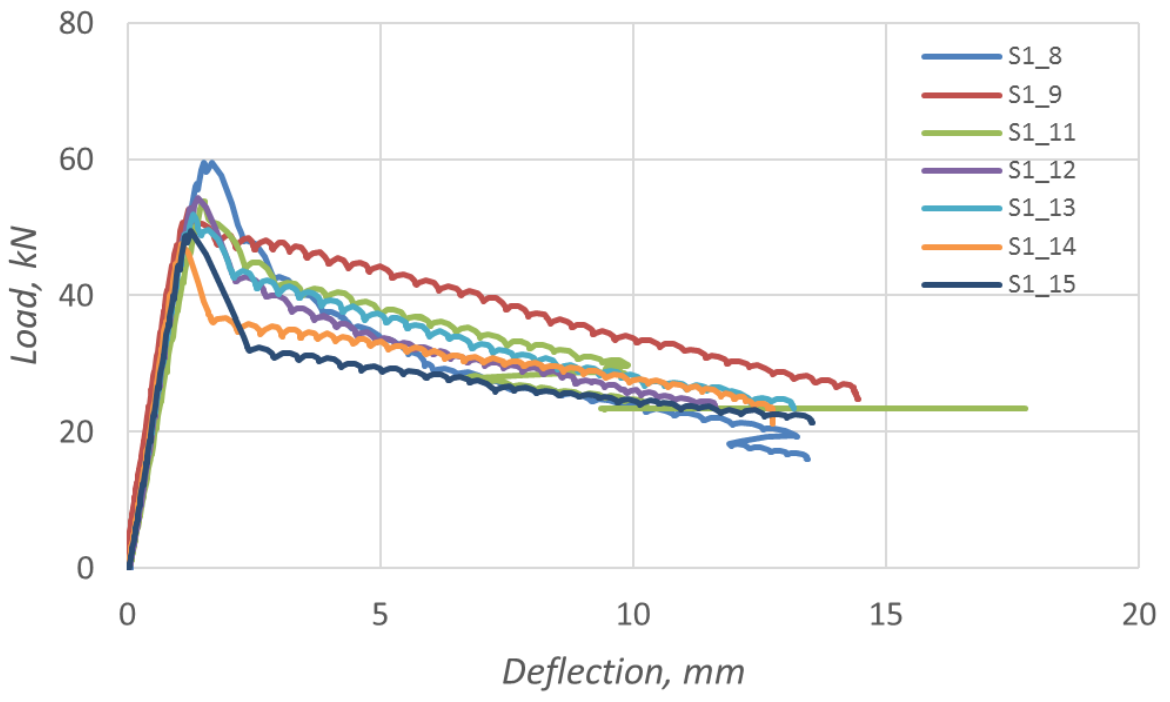

Fig. 5. Load-deflection relationship diagram for ASTM 1550

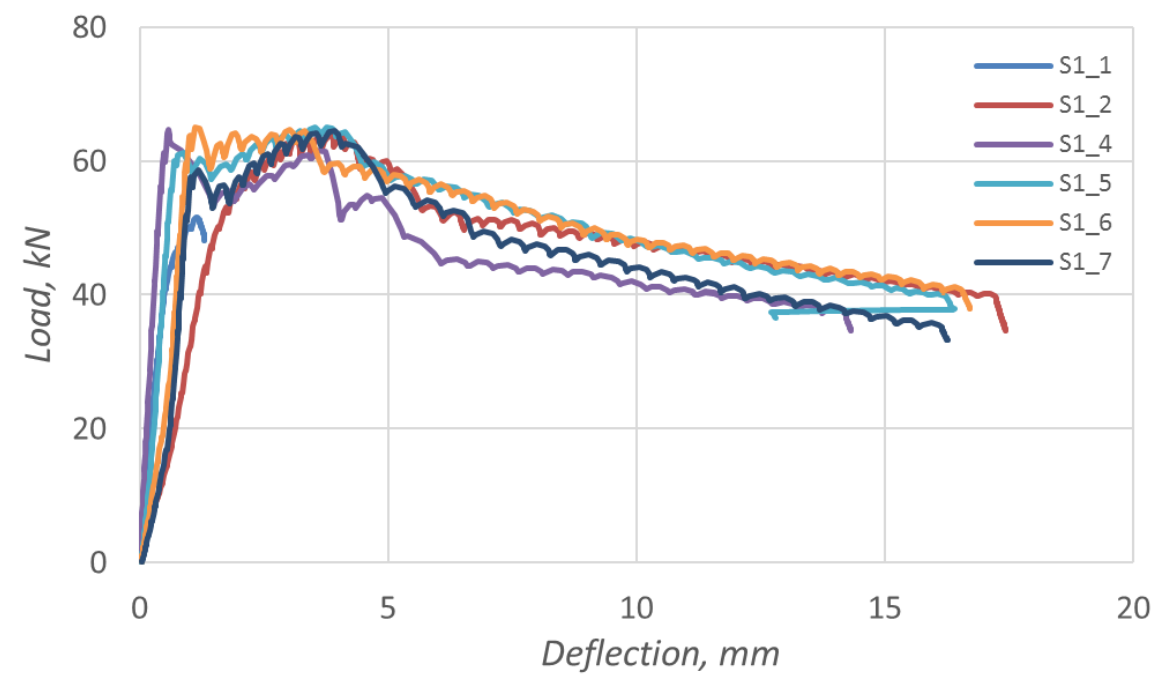

Fig. 6. Load-deflection relationship diagram for SIA 162/6 


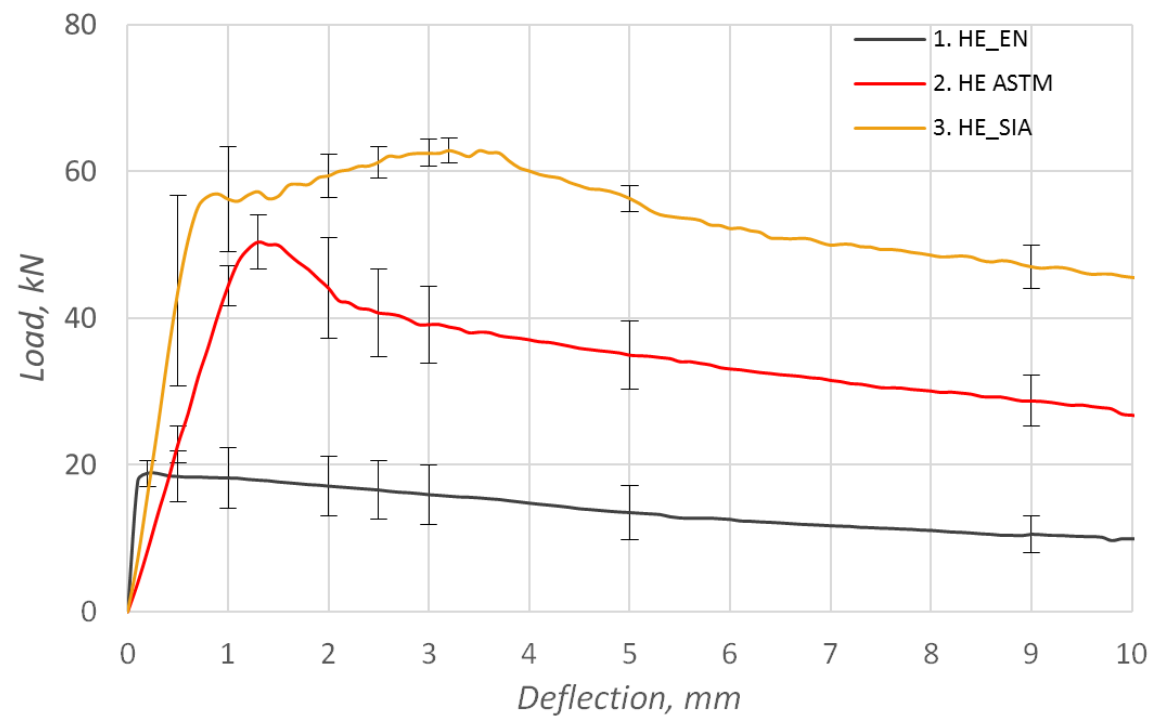

Fig. 7. Determined mean load-deflection relationships for three applied flexural performance testing methods (EN14651, ASTM 1550C and SIA 162/6); vertical error bars indicate one standard deviation

Table 2

Mean results of the load-deflection measurements according to the three applied methods

\begin{tabular}{|c|c|c|c|c|c|c|}
\hline \multirow{2}{*}{$\begin{array}{c}\text { Deflection, } \\
\text { mm }\end{array}$} & \multicolumn{2}{|c|}{ 1. HE_EN } & \multicolumn{2}{c|}{ 2. HE ASTM } & \multicolumn{2}{c|}{ 3. HE_SIA } \\
\cline { 2 - 7 } & $\begin{array}{c}\text { Mean } \\
\text { value, } \mathbf{k N}\end{array}$ & $\begin{array}{c}\text { Coefficient } \\
\text { of } \\
\text { variation }\end{array}$ & $\begin{array}{c}\text { Mean } \\
\text { value, kN }\end{array}$ & $\begin{array}{c}\text { Coefficient } \\
\text { of } \\
\text { variation }\end{array}$ & $\begin{array}{c}\text { Mean } \\
\text { value, kN }\end{array}$ & $\begin{array}{c}\text { Coefficient } \\
\text { of } \\
\text { variation }\end{array}$ \\
\hline 0.2 & $\mathbf{1 8 . 8 6}$ & $\mathbf{9 . 4 \%}$ & 8.45 & - & 16.22 & - \\
\hline 0.5 & 18.42 & $18.5 \%$ & 22.79 & $11.0 \%$ & 43.67 & $29.7 \%$ \\
\hline 1 & 18.22 & $22.6 \%$ & 44.38 & $6.3 \%$ & 56.21 & $12.8 \%$ \\
\hline 1.3 & 17.92 & - & $\mathbf{5 0 . 3 7}$ & $\mathbf{7 . 4 \%}$ & 57.21 & - \\
\hline 2.5 & 16.57 & $24.4 \%$ & 40.69 & $14.8 \%$ & 61.26 & $3.5 \%$ \\
\hline 3 & 15.93 & $25.3 \%$ & 39.11 & $13.5 \%$ & 62.47 & $3.0 \%$ \\
\hline 3.2 & 15.73 & - & 38.79 & - & $\mathbf{6 2 . 8 3}$ & $\mathbf{2 . 6 \%}$ \\
\hline 5 & 13.51 & $27.2 \%$ & 34.94 & $13.4 \%$ & 56.30 & $3.1 \%$ \\
\hline 9 & 10.54 & $24.3 \%$ & 28.71 & $12.1 \%$ & 46.98 & $6.3 \%$ \\
\hline
\end{tabular}

\subsection{Structural design}

To evaluate the practical consequences of the method that is used to determine the design values of the SFRC composite, it was chosen to perform structural design calculations of a typical civil engineering structure (pile supported flooring slab of an industrial warehouse) where such a material could be economically applied.

Thus, a structural design is made using the test results, as shown above in Fig. 7, to see the influence of the tests on the outcomes of the designs. The following structural design methodology is based on ACI544.6R-15 [10; 11].

For a better comparison, it is set that in the input data of loads, piling layout is equal to all of the cases. The data are chosen to represent a mid-range loaded warehouse, thus $30 \mathrm{kN} \cdot \mathrm{m}^{-2}$ on $4.0 \times 4.0 \mathrm{~m}$ pile grid, each pile having $800 \mathrm{~mm}$ caps. The used input data to the calculations and the results of the calculations are shown in Table 3. 


\section{Input data for structural design of a piled slab} using the data from the tests

\begin{tabular}{|c|c|c|c|c|c|}
\hline \multirow{2}{*}{ Test method } & \multicolumn{3}{|c|}{ Pilegrid information } & $\begin{array}{l}\text { Loading } \\
\text { intensity }\end{array}$ & $\begin{array}{l}\text { Determined thickness } \\
\text { of the slab }\end{array}$ \\
\hline & $x, \mathbf{m}$ & $y, \mathrm{~m}$ & Pilehead $D, \mathrm{~m}$ & $q, \mathrm{kN} \cdot \mathrm{m}^{-2}$ & $h, \mathrm{~mm}$ \\
\hline EN14651 & \multirow{3}{*}{4.0} & \multirow{3}{*}{4.0} & \multirow{3}{*}{0.8} & \multirow{3}{*}{30} & 235 \\
\hline ASTM1550C & & & & & 240 \\
\hline SIA162/6 & & & & & 210 \\
\hline
\end{tabular}

\section{Discussion \& Conclusions}

From the results presented in Table 2, it can be seen that the coefficient of variation is decreased from $9.4 \%$ for EN14851 as the maximum to $2.6 \%$ for SIA162/6 as the minimum. This reduction can be attributed to statical redundancy of the testing method, where the simply supported beam of EN14651 is the least redundant and the continuously supported slab of SIA162/6 is the most redundant.

Conclusions of the investigation of concrete specimen testing in flexure include the following.

1. Usage of different testing methods yields different input parameters for the design of structures;

2. The largest slab thickness was determined from the results ofthe specimen tested according to ASTM1550C.

3. The leanest slab thickness was determined from the results of the specimen tested according to SIA162/6.

4. The test methods of the round panels allow for the development of multiple cracks, as opposed to a single crack of the beam test, resulting in a reduced variability of the results due to inherent problems with specimen production of the beam test.

\section{Acknowledgements}

In accordance with the contract No. 1.2.1.1/18/A/007 between "VMKC" Ltd. and the Central Finance and Contracting Agency, the study is conducted by "Primekss" Ltd. with support from the European Regional Development Fund (ERDF) within the framework of the project "Competence center of smart materials and technologies".

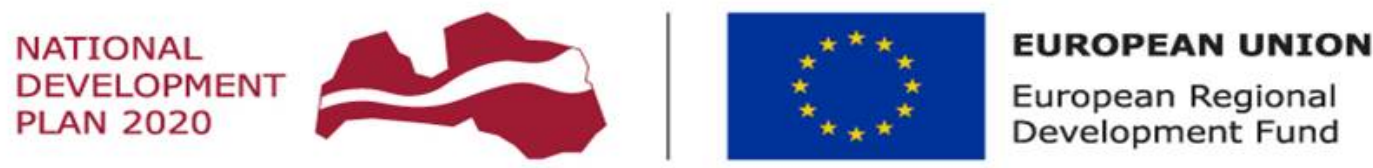

$$
\text { I N V E S T I N G I N YOU R F U T U R E }
$$

\section{References}

[1] Destrée X. Twincone Steel fiber Reinforced Structural Concrete. Fiber Reinforcded concrete Modern developments, The University of British Columbia, Vancouver, Canada. 1995.

[2] Destrée X. Structural Application of Steel Fibre as Only Reinforcing in free suspended elevated Slabs: Conditions-Design-Examples, $n^{\circ} 97$, p. 1073, Vol .2, Sixth RILEM Symposium on FibreReinforced Concretes (FRC) BEFIB 2004, Varenna, Italy.

[3] Destrée X. Steel Fibre Only Reinforced Concrete in free Suspended Slabs: A Rapid Design Method and its Background. International Workshop on Fiber Reinforced Concrete, Nov 17-18, 2014 Stanford University - Technical University of Denmark.

[4] Destrée X., Pease B, "Reducing CO2 Emissions of Concrete Slab Constructions with the PrimeComposite Slab System,” American Concrete Institute (ACI) Special Publication 299, 2015, pp. 1-12.

[5] ACI Committee 223, "ACI 223R-10 - Guide for the Use of Shrinkage-Compensating Concrete," American Concrete Institute, 2010, 16 p. 
[6] Huanan H., Boxin W., Jianting L., "Performance on steel fiber reinforced self-stressing concrete", Key Engineering Materials Vols. 400-402, 2009, pp. 427-432.

[7] BS EN12350-2:2019 Testing fresh concrete. Slump test

[8] European Committee for Standardization, EN14651:2005:E, "Test method for metallic fibered concrete - Measuring the flexural tensile strength (limit of proportionality (LOP), residual)", Brussels, 2005.

[9] ASTM International, "ASTM1550-12a Standard Test Method for Flexural Toughness of Fiber Reinforced Concrete (Using Centrally Loaded Round Panel)", 2012.

[10] Sociétésuisse des ingénieurset des architects, "SIA162/6Bétonrenforcé de fibresmétalliques. Terminologie. Principes. Calculetdimensionnement. Matériaux. Exécution. Sécurité au travail. Prestation et métré.", Zurich, 1999.

[11] ACI Committee 544, "ACI 544.6R-15 - Report on Design and Construction of Steel FiberReinforced Concrete Elevated Slabs", American Concrete Institute, 2015. 